\title{
Operative Treatment of Scaphoid Nonunion
}

\author{
SHERIEF N. AMIN, M.D.; AYMAN M. MANSOUR, M.D.; HAMADA M. ABDELAAL, M.Sc. and \\ AHMED S. MOUSTAFA, M.Sc.
}

The Department of Orthopedic Surgery, Faculty of Medicine, Cairo University

\begin{abstract}
Background: Scaphoid nonunion result in a predictable pattern of wrist arthrosis. To minimize the incidence of arthrosis, the goal of treatment should be consolidation of the fracture of the scaphoid in anatomic alignment.

Aim of Study: To evaluate different means of treatment of scaphoid nonunion and evaluate its clinical results.

Patients and Methods: This study was conducted at ELHelmya Military Hospital and Kasr El-Ainy Hospital during the period from 2011 to 2016 on fifty patients diagnosed as non-united fracture scaphoid and operated upon by fixation and graft if needed, then followed-up for a period of at least 18 months. Patients were 49 male and one female with an average age of 23 years. All operative management and followup.
\end{abstract}

Results: This study proved that operative treatment of scaphoid nonunion can be summarized as follows: Grade I,II,III according to Slade and Geissler's classification can be treated by percutaneous or open fixation by Herbert screw even if the nonunion in prox. Pole. Grade IV/V/VI we have to open volarly for waist or dorsally for prox. Pole and fixation with bone graft from iliac crest or distal radius.

Conclusion: This study proves that the goal of treatment of scaphoid nonunion should be consolidation of the fracture in anatomic alignment. scaphoidnonunions with severe collapse and humpback deformity must be approached volarly with interposition of an intercalary bone graft and internal fixation. A dorsal approach to proximal scaphoid nonunions allows immediate access for removing the necrotic bone from small proximal pole nonunions and internal fixation.

Key Words: Scaphoid-Osteonecrosis - Fixation-Bone graft.

\section{Introduction}

SCAPHOID fracture is the most common carpal fracture. It accounts for approximately $60 \%$ to $90 \%$ of carpal fractures and $11 \%$ of hand fractures. The term "scaphoid" is derived from the Greek

Correspondence to: Dr. Ahmed S. Moustafa, E-Mail:drsalehwrist1981@yahoo.com word "skaphe," which means skiff and is named for its likeness to a boat. However, the 3 - dimensional shape of the scaphoid is more complex [1]

Classifying scaphoid fractures by dividing the scaphoid into thirds according to its length is simple and easy to understand, but the distinct groups of fracture at the tuberosity, distal articular surface, and proximal pole of the scaphoid are neglected. The Mayo classification for scaphoid fractures is commonly used in clinical practice and can address these distinct fracture groups [2].

Five to $30 \%$ of scaphoid fractures evolve towards non-union. Without treatment, this leads to periscaphoid arthritis and carpal collapse with dorsal intercalated segment instability (DISI) deformity of the lunatum [3].

The optimal treatment for established scaphoid nonunion remains controversial even though some scaphoid nonunions cause few symptoms and little disability, evidence seems to suggest a distinct progression of arthritic changes over time, affecting first the distal scapho-radial joint and later progressing to the scaphocapitate and captolunate joints [4].

\section{Aim of the work:}

The study is targeting to evaluate efficacy, advantages and disadvantages of different means of treatment of scaphoid nonunion this study also aims at detection of the factors that may have a role in determining the final outcome.

\section{Patients and Methods}

Between 2011 and 2016 fifty patients had been diagnosed asnon-united fracture scaphoid and were operated upon by fixation and graft if needed, then followed-up for a period of at least 18 months. 
Patients were 49 male and onefemale with an average age of 23 years. All operative management and follow up were at El-Helmya Military Hospital and Kasr El-Ainy Hospital.

The patients were classified according to Slade $\&$ Geissler's classification system for scaphoid nonunion.

The study included patients with Scaphoidnonunions without substantial bone loss: Grades. I (4 to 12 weeks delayed presentation), grade II (fibrous union), and grade III (gap $<1 \mathrm{~mm}$ ), correctly aligned and perfused scaphoid nonunions with substantial bone loss. Grade IV (gap $>1 \mathrm{~mm}$ but $<5 \mathrm{~mm}$ ) grade $\mathrm{V}$ (gap $>5 \mathrm{~mm}$ ) and deformity, Proximal pole nonunion and avascular necrosis.

While patients with scaphoid non-union advanced collapse (SNAC), complicated fracture like trans scaphoid perilunar dislocations and associated fracture in the distal radius or other carpal bones were excluded from the study.

\section{All patients were subjected to the following} procedures:

Past history: Patients were inquired about previous trauma to the ipsilateral and contralateral wrist or limb for accuracy of comparison of range of motion. No history of previous trauma was detected in all patients. History of chronic illness or previous operations was also inquired for.

Clinical examination: All patients were subjected to clinical examination which fulfilled the following steps:

Inspection: The wrist was examined fordeformity, muscle wasting or scars.

\section{Palpation:}

Anatomical snuffbox, radial styloid, 1 st carpometacarpal joint and tendons of the $1{ }^{\text {st }}$ and 3 rd compartments, Lister's tubercle, Scapholunate joint, the lunate and the capitate were examined for tenderness.

Median nerve was examined for entrapment neuropathy. Finally, distal scaphoid tubercle was palpated at the radial aspect of the distal wrist crease in line with the thumb metacarpal.

\section{Range of Motion (ROM) \& Grip strength:}

Palmar and dorsal flexion, ulnar and radial deviations were measured and documented. Grip strength measured bilaterally by dynamometer.
Recording of preoperative pain score by VAS:

Preoperative functional score by DASH:

Radiological evaluation:

- X-ray wrist PA, lateral and scaphoid views were done for the injured and contralateral wrist. SL, $\mathrm{RL}$ and IS angles were measured for both injured and contralateral wrist

- Computed tomography: C.T wrist with coronal, sagittal and reconstructive cuts was done in all patients, C.T is beneficial to study:

1- Gap size: 5 patients with gap $<5 \mathrm{~mm}, 45$ patients with gap > $5 \mathrm{~mm}$.

2- Cyst: 4 patients in the sample presented with cyst.

3- Scaphoid and carpal alignment: 13 patients showed malalignement including 2 patients showed humpback deformities.

- Magnetic Resonance Imaging (MRI): MRI was done only in suspicious cases of AVN prox. pole, 6 cases were studied by MRI, and only one patient showed AVN prox. pole scaphoid.

Cases were classified according to Slade \& Geissler's classification system for scaphoid nonunion:

- Twopatients (4\%) gradeI (4 to 12 weeks delayed presentation):

One patient operated upon by percutaneous volar and the other patient with percutaneous dorsaltechnique.

- Five patients (10\%) grade II (fibrous union):

One patient operated upon by opendorsal technique without graftand 4 patients with open volar technique without graft.

- Three patients (6\%) grade III (gap <1 mm):

Two of them operated upon by open volar technique without graft and one by percutaneous volar technique.

- Twenty seven patients (54\%) grade IV (gap >1 mm but $<5 \mathrm{~mm}$ ):

16 patients operated upon by openvolar technique and bone graft from distal radius, 5 patients by open volar technique and bone graft from iliac crest, one patient by open dorsal technique with graft from dorsal radius, 2 patients by open dorsal technique and graft from iliac crest and 3 patients with percutaneous volar technique.

- Thirteen patients (26\%) grade V (gap >5mm):

9 patients operated upon by open volar technique and bone graft from iliac crest, 2 patients 
by open volar technique and bone graft from distal radius, one patient with AVN by open volar technique and vascularized medial femoral condyle grafting and one patient with open dorsal technique without graft.

\section{Associated injuries:}

No associated injury detected by neither past history nor examination in the sample.

Laboratory investigations: Routine preoperative laboratory investigations were done including liver and kidney function, hemoglobin concentration and blood sugar.

\section{Surgical techniques:}

The patient is positioned supine on the operating table with a radiolucent hand table. General anesthesia used. A pneumatic tourniquet is applied on the proximal arm. Following prepping and draping of the limb, the forearm is supinated in volar approach either open or percutaneous and pronated in the dorsal approach.

\section{1-Percutaneous volar technique:}

Volar approach based on the work of Jeon et al., [5] The point of entry of the wire in volar approach was actually through the trapezial ridge. A wire of the same length is used to measure screw length, after which guide wire is advanced to radius to prevent wire pullout during drilling.

\section{2-Percutaneous dorsal technique:}

Dorsal approach based on Slade et al., [3] In the dorsal approach blunt dissection to the bone through the snip wound was done to free out extensor tendons before drilling and screw application to make sure that they are not tethered during the procedure.

\section{3-Anterior wedge grafting:}

This technique was based on the work of Fernandez [12] with some modifications, a palmar hockey-stick incision along the FCR, extended obliquely toward the thenar eminence. The anterior capsule is incised from the distal radius to the scaphotrapezoidal joint to expose the most Palmar-radial corner of the scaphoid without damaging its blood supply.

Sclerotic or irregular borders of the nonunion site are resected with bony ronguers and curette to flat bony surfaces. Cystic defects are curetted and filled with cancellous bone chips.

A bicortical or tricortical graft is harvested from the iliac crest, along with additional curetting of cancellous bone. The graft is kept in aspirated blood from the iliac wound until ready for use and the graft is sculpted to the correct dimensions using bone cutting. The bone graft is impacted into the defect and scaphoid alignment and posture checked with fluoroscopy. A guide wire is advanced from distal to proximal across the scaphoid and intercalated graft, after reaming and measuring the appropriate length of the screw, a correctly sized cannulated screw is inserted over the guide wire correcting the deformity and stabilizing the graft

\section{4- Open dorsal approach:}

The forearm is pronated and a longitudinal skin incision $2 \mathrm{~cm}$ in length is placed beginning at the proximal aspect of the Lister's tubercle extending along the axis of the third metacarpal.

Full-thickness skin flaps are raised and the extensor retinaculum of the third compartment is incised immediately distal to the Lister's tubercle, releasing the extensor pollicis longus (EPL) tendon. The extensor digitorum communis (EDC) tendons are gently retracted ulnarly while the extensor carpi radialis brevis (ECRB) and longus (ECRL) tendons are retracted radially with the EPL to expose the underlying joint capsule which is incised to expose the non-union site.

The scaphoid is flexed and a starting point for the guide wire is chosen 1 to $2 \mathrm{~mm}$ radial to the insertion of the SLIL in the sagittal midline of the scaphoid.

The wire is directed freehand toward the scaphoid tubercle, and position checked with fluoroscopy. When it is in an ideal position, a correctly sized cannulated screw is inserted over the guide wire and the wire withdrawn.

\section{Postoperative management protocol:}

A short arm cast excluding the thumb wasapplied for six weeks, followed by a removable splint for four weeks. Patients were allowed to move the wrist after removal of the cast, but instructed to avoid contact sports or full loading until union was achieved.

\section{Follow-up:}

\section{Early postoperative:}

Clinical evaluation: Wound care, examination for hand edema and capillary circulation. Full range of motion of the fingers was encouraged. Radiological evaluation: Postoperative X-rays were examined for screw positionand lengthe.g. clearance of the scaphotrapezial joint from the screw head and leading threads not penetrating the dorsal cortex into radio-scaphoid articulation, screw di- 
rection and its relation to the plane of the fracture, measuring of SL, RL and IS angles.

\section{Late postoperative:}

Clinical examination at time of union, at 6 months and at 18 months for evaluation of the functional outcome DASH score,pain score by VAS, grip strength and ROM. Radiological examination at 4 weeks and every 2 weeks until 10 weeksfor assessment of union, carpal alignment, measuring SL, RL and IS and evidence of complications; then at 6 months, after 12 months and finallyat 18 months for follow-up.

\section{Assessment of union:}

Absence of fracture site tenderness and presence of bone trabeculae that cross the fracture site in 5 scaphoid views [PA-lateral-ulnar deviated PA- $45^{\circ}$ oblique PA (semi-pronated) - $45^{\circ}$ oblique AP (semisupinated)] (43) were used as signs of union.CT was performed in suspicious cases.

\section{Statistical methods:}

IBM SPSS statistics (V. 24.0, IBM Corp., USA, 2016) was used for data analysis. Data were expressed as Mean \pm SD for quantitative parametric measures. The following tests were done: (1) Comparison between two independent mean groups for parametric data using Student $t$-test. (2) Comparison between 2 dependent groups for parametric data using Paired $t$-test. (3) Comparisonbetween more than 2 patient groups for parametric data using Analysis of Variance (ANOVA). (4) Pearson correlation test to study the possible association between each two variables among each group for parametric data. The probability of error at 0.05 was considered significant, while at 0.01 and 0.001 are highly significant.

\section{Results}

Fifty cases of non-united scaphoid fractures treated by various methods of operative procedures were studied.

Tenderness over the lunate, capitate or scapholunate joint could not be differentiated from the fracture pain. Forty patients reported that this pain was affecting their jobs or daily lives. There was no sign of nerve entrapment or compartment syndrome. There was no muscle wasting or scars of previous operations. Thirty four patients were subjected to paid sick leaves.

Age:

The youngest patient in this study was 18 years old and the eldest patient was 30 years old Table (1).
Table (1): Age incidence.

\begin{tabular}{ccc}
\hline Age (years) & No. of patients & Percentage \\
\hline$\leq 20$ & 16 & 32 \\
$>20$ & 34 & 68 \\
\hline
\end{tabular}

Sex:

Male patients were 49 while female patient was 1 (Table 2).

Table (2): Sex incidence.

\begin{tabular}{lcc}
\hline Sex & No. of patients & Percentage \\
\hline $\mathrm{M}$ & 49 & 98 \\
$\mathrm{~F}$ & 1 & 2 \\
\hline
\end{tabular}

\section{Hand dominance:}

Forty six patients were right handed. And 4 patients were left handed. Right side was affected in 35 and left side was affected in 15 (Table 3).

Table (3): Hand dominance \& affected side.

\begin{tabular}{lcc}
\hline Affected side & No. of patients & Percentage \\
\hline Dominant & 33 & 66 \\
Non-dominant & 17 & 34 \\
\hline
\end{tabular}

\section{History of trauma:}

Forced hyperextension during axial loading was found to be the main cause of facture. Fall on outstretched hand (FOOSH) was the most common mode of trauma causing the fracture in 23 patients; motorcycle accident was the second common mode of trauma in 14 patients and during athletic activity was found in 13 patients (Table 4).

Table (4): Mode of trauma.

\begin{tabular}{lcc}
\hline Mode of trauma & No. of patients & Percentage \\
\hline FOOSH & 23 & 46 \\
Motorcycle accident & 14 & 28 \\
Athletic competition & 13 & 26 \\
\hline
\end{tabular}

Duration since injury to surgical procedure:

The duration ranged from 5 weeks to 60 weeks from injury to surgical procedure in the patients of our study with average 13.2 weeks (Table 5).

Table (5): Duration of trauma.

\begin{tabular}{lcc}
\hline Duration in weeks & No. of patients & Percentage \\
\hline $5-20$ & 35 & 70 \\
$21-36$ & 10 & 20 \\
$37-52$ & 4 & 8 \\
$>52$ & 1 & 2 \\
\hline
\end{tabular}

No patient gave history or presented with associated injury. 


\section{Fracture union:}

Forty eight patients' shows full union at mean of time of 11.54 weeks (6-34 weeks).

Nineteen patients were nonsmokers and showed time of union at mean of 12.42 weeks. 29 patients were smokers and showed time of union at mean of 20.68 weeks. The two patients who showed nonunion were heavy smokers so there was a highly significant ratio between smoking and time of union. $(p=0.001)$.

Fracture union in relation to gap size: Patients were classified according to gap size into two groups 5 patients with gap $<5 \mathrm{~mm}$ and 45 patients with gap $>5 \mathrm{~mm}$. No relation was found between gap size and delay of time to union.
The determinant factor was the time to operation; the longer the time since injury, the longer the time the fracture needed to heal.

\section{Assessment of pain by VAS:}

Postoperatively there was less pain, either in the snuffbox or with wrist movement, and the VAS (visual analogue scale) improved from a mean of 1.71 (0.3 to 7) preoperative, to a mean of 1.45 (0 to 7$)$ at 12 months and this improvement is ofnonsignificant value $(p=0.129)$.

At 18 months, VAS mean was 0.86 (0 to 5.6), and this improvement is ofhighly significant value ( $p=0.001)$ compared to preoperative value.

Case (1): A 28-year-old man with nonunion waist of the Lt. scaphoid G IV of 18 weeks duration; operated by open volar approach using graft from distal radius fixed with Herbert screw. Union after 20 weeks and the final result at 18 months was Pain score 0, DASH score $=11.7$.
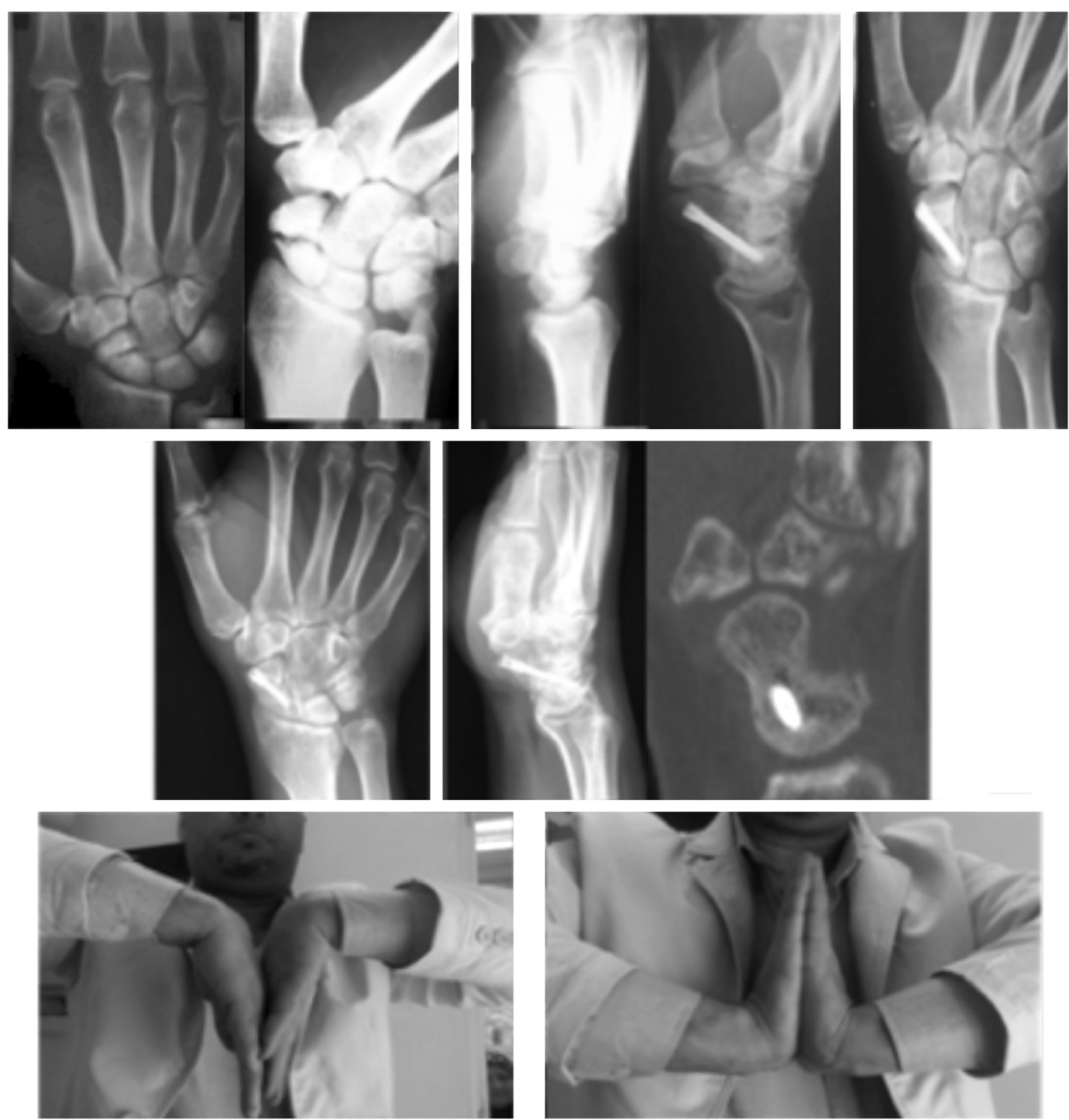

Fig. (1): Top: Preoperative (PA; lateral), Postoperative radiographs at 3 months show realignment of the scaphoid and the lunate, Bottom: One year follow-up. Computed tomography scan shows full union. With F/E=35/45. 
ROM:

The mean pre-operative range of motion was $47.04^{\circ}\left(20^{\circ}\right.$ to $\left.70^{\circ}\right)$ for flexion/extension and $14.02^{\circ}$ $\left(7^{\circ}\right.$ to $\left.30^{\circ}\right)$ for RD/UD. The postoperative range of motion at 3 months improved to mean of $46.44^{\circ}$ $\left(20^{\circ}\right.$ to $\left.70^{\circ}\right)$ and $13.94^{\circ}\left(7^{\circ}\right.$ to $\left.30^{\circ}\right)$ for flexion/ extension and RD/UD respectively. $(p=0.725)$ and $(p=0.693)$.

The postoperative range of motion at 12 months improved to mean of $52.72^{\circ}\left(30^{\circ}\right.$ to $\left.75^{\circ}\right)$ and $19.28^{\circ}$ $\left(10^{\circ}\right.$ to $\left.35^{\circ}\right)$ for flexion/extension and RD/UD respectively. $(p=0.002)$ and $(p=0.001)$.

The postoperative range of motion at 18 months improved to mean of $53.88^{\circ}\left(30^{\circ}\right.$ to $\left.75^{\circ}\right)$ and $19.08^{\circ}$ $\left(10^{\circ}\right.$ to $\left.35^{\circ}\right)$ for flexion/extension, $\mathrm{RD} / \mathrm{UD}$ respectively. $(p=0.001)$ and $(p=0.001)$.

\section{Grip strength:}

The mean pre-operative grip strength was $33.34 \mathrm{~kg}$ (20kg to50kg), the postoperative grip strength at 3 months improved to $34.3 \mathrm{~kg}$ (30 kg to $52 \mathrm{~kg}) .(p=0.212)$.

The postoperative grip strength at 12 months improved to mean of $40.86 \mathrm{~kg}$ (30kg to $60 \mathrm{~kg}$ ). $(p=0.001)$ and at 18 months improved to a mean of $40.86 \mathrm{~kg}$ (30kg to $60 \mathrm{~kg}) .(p=0.001)$.

\section{DASH score:}

Pre-operatively, the mean of DASH score was 16.268 (3.3-28.3). Post operatively at 3 months improved to $14.206(0-30)(p=0.003$ and at 12 months improved to $10.762(0-26.2)$. $(p=0.001)$.

\section{Radiologically:}

The mean pre-operative SL angle was $57.92^{\circ}$ $\left(45^{\circ}\right.$ to $\left.70^{\circ}\right)$ and for RL angle $-3.9^{\circ}\left(-15^{\circ}\right.$ to $\left.7^{\circ}\right)$ and $33.34^{\circ}\left(30^{\circ}\right.$ to $\left.40^{\circ}\right)$ for IS angle. The postoperative SL angle, $\mathrm{RL}$ angle and IS angle after onemonths improved to mean of $47.74^{\circ}\left(40^{\circ}\right.$ to $\left.65^{\circ}\right),-0.72^{\circ}\left(-5^{\circ}\right.$ to $\left.5^{\circ}\right)$ and $29.24^{\circ}\left(24^{\circ}\right.$ to $\left.35^{\circ}\right)$. $(p=0.001),(p=0.001)$ and $(p=0.001)$ respectively, (highly significant).

Case (2): A 25-year-old man with nonunion waist of the Rt. scaphoid G II of 15 weeks duration; operated by open volar technique fixed with Herbert screw, smoker. Final result was Pain score 0, DASH score $=10$.
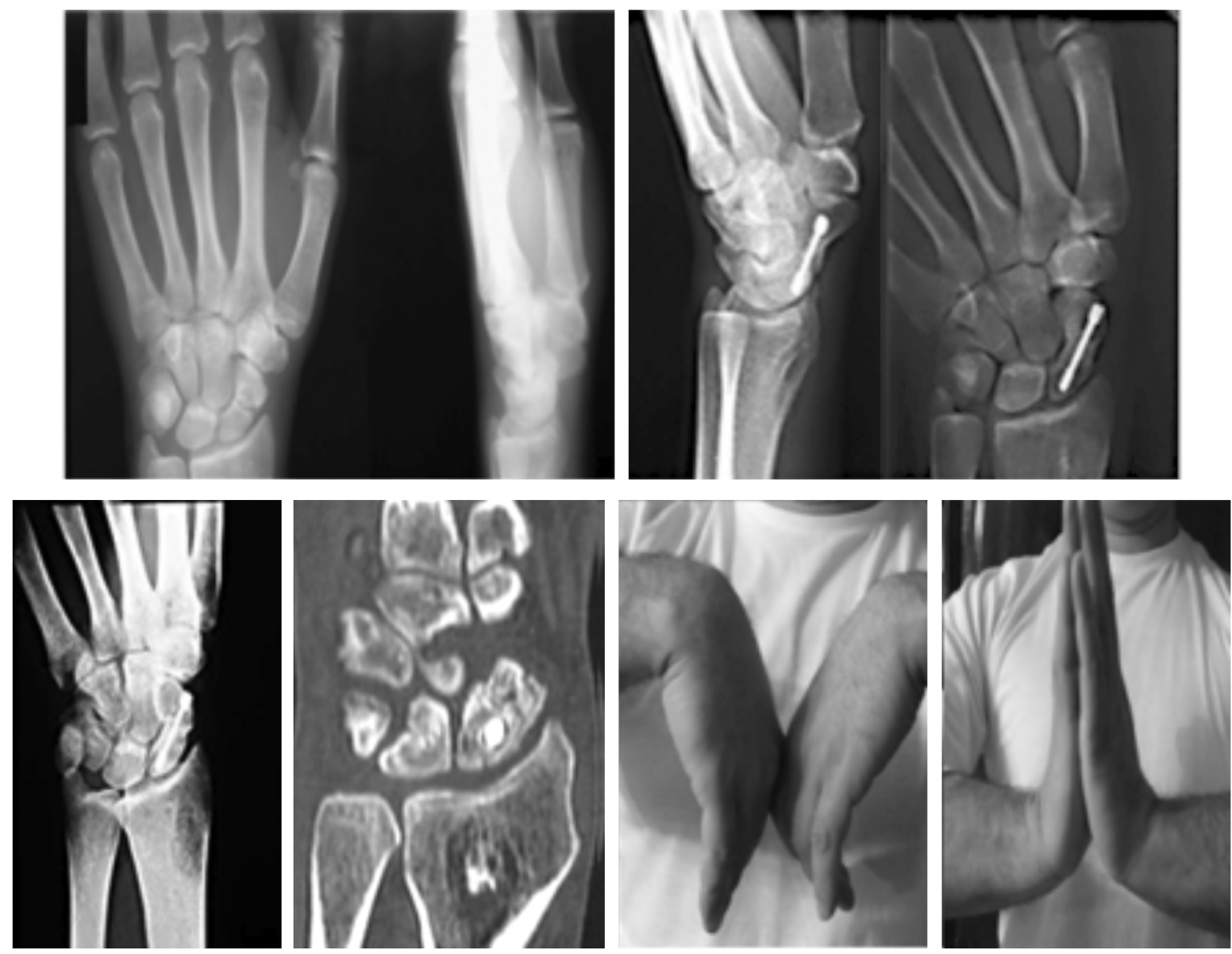

Fig. (2): Top: Preoperative (PA; lateral), Postoperative radiographs show compression of nonunion with good alignment. Bottom One-year follow-up with partial union Computed tomography scan shows union but with backing out of the screw. 
After 3 months to mean of $46.78^{\circ}\left(40^{\circ}\right.$ to $\left.54^{\circ}\right)$, $0.58^{\circ}\left(4^{\circ}\right.$ to $\left.3^{\circ}\right)$ and $28.42^{\circ}\left(24^{\circ}\right.$ to $\left.32^{\circ}\right)$. $(p=0.001),(p=0.001)$ and $(p=0.001)$ for $\mathrm{SL}, \mathrm{RL}$ and IS angle respectively.
At 18 months the mean was $44.78^{\circ}\left(40^{\circ}\right.$ to $\left.52^{\circ}\right)$, $0.34^{\circ}\left(1^{\circ}\right.$ to $\left.2^{\circ}\right)$ and $27.46^{\circ}\left(24^{\circ}\right.$ to $\left.30^{\circ}\right)$. $(p=0.001),(p=0.001)$ and $(p=0.001)$ for SL, RL and IS angle respectively.

Case (3): A 33-year-old man with nonunion waist of the Lt. scaphoid G V with cyst formation, of 24 weeks duration; with slight dorsal intercalated segment instability deformity operated by open volar wedge iliac graft fixed by Herbert screw Union after 12 weeks and the final result at 18 months was Pain score 1.7, DASH score $=10.8$.
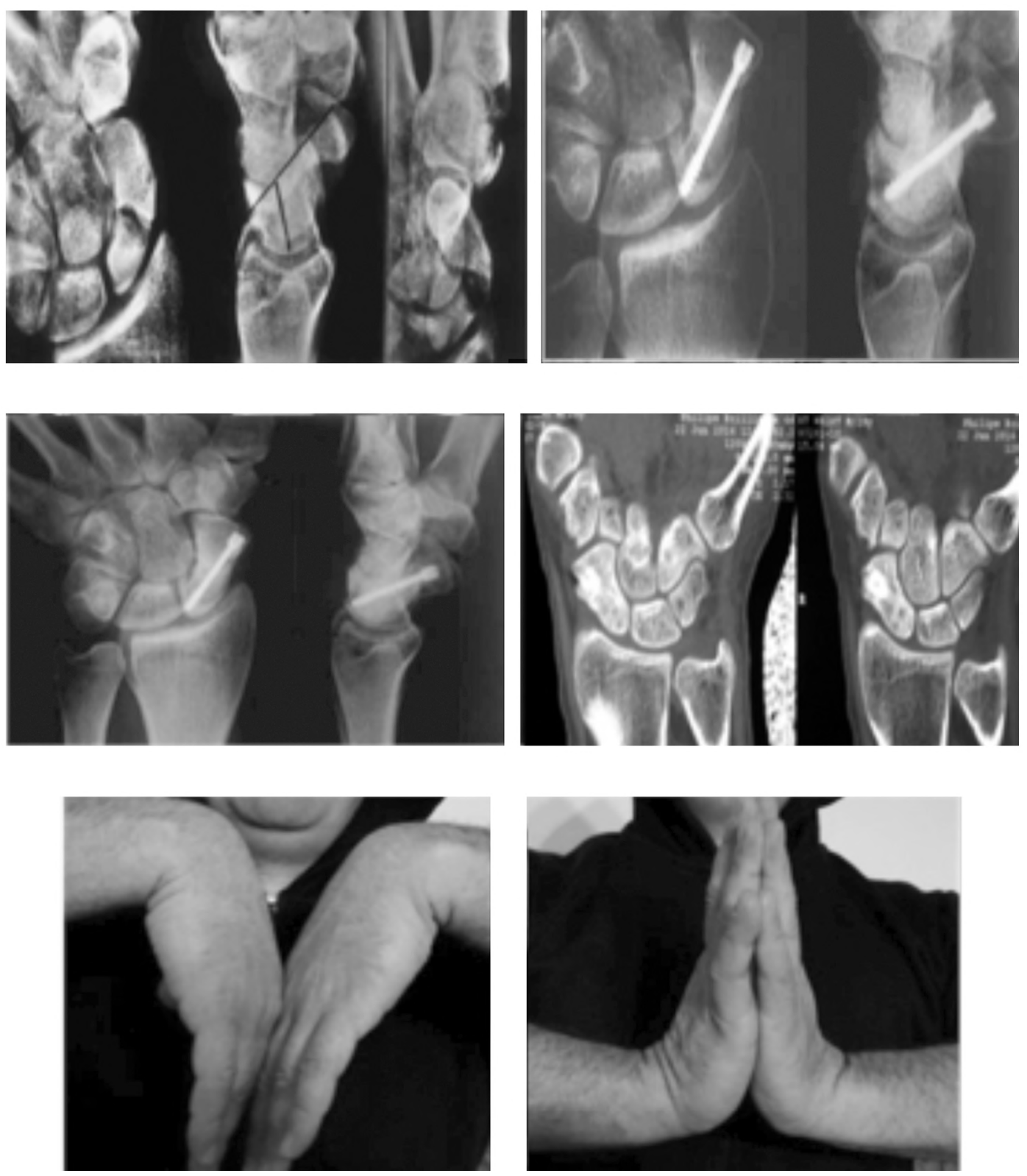

Fig. (3): Top: Preoperative (PA; lateral, semi pronated). Six months follow-up Postoperative radiographs show realignment of the scaphoid and the lunate. Middle: One year follow-up, Computed tomography scan shows full unions. Bottom: $\mathrm{F} / \mathrm{E}=40 / 5$. 
Case (4): A 22-year-old man with nonunion of the Rt. scaphoid G V prox. pole of 60 weeks duration; with slight dorsal intercalated segment instability deformity operated by open dorsal approach using graft from iliac crest fixed by Herbert screw. Union after 18 weeks and the final result at 18 months was Pain score 0 , DASH score $=15$.
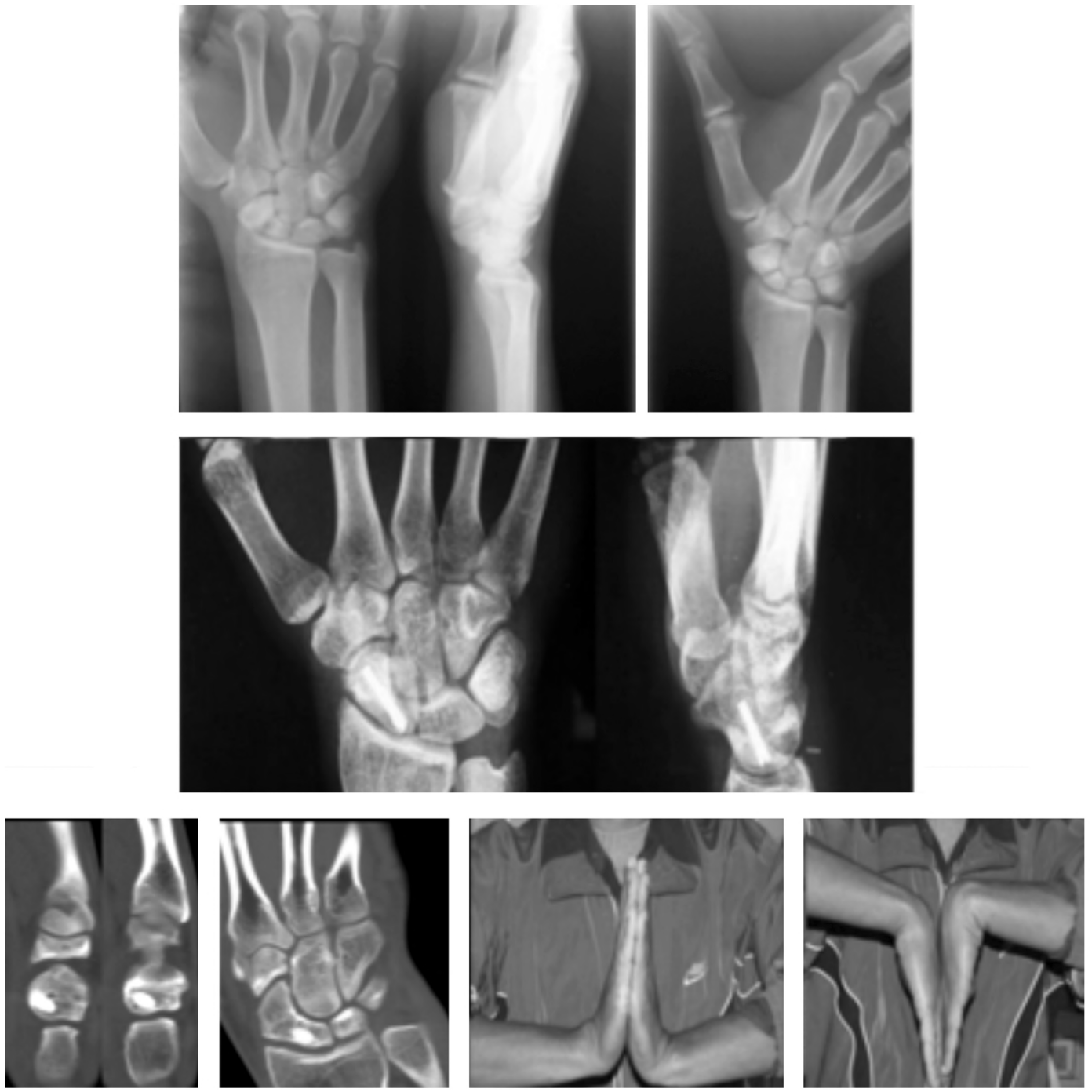

Fig. (4): Top: Preoperative (PA; lateral). Middle: Three-month follow-up Postoperative radiographs show realignment of the scaphoid and the lunate. Bottom: One year follow-up, Computed tomography scan shows full union With $\mathrm{F} / \mathrm{E}=40 / 50$.

\section{Discussion}

The scaphoid, like the talus or head of femur, has an almost complete cartilaginous surface except for small portions on the dorsal and palmar aspect. Consequently, it depends on an intra-osseous healing process especially in the proximal one third that is supplied from intra-osseous vessels. Therefore, there is greater possibility of a prolonged healing time and non-union in the more proximal fracture [5].

An important milestone in the surgical treatment of scaphoid fractures was the introduction of the headless screw. The introduction of cannulated screws has made it possible to fix the scaphoid fractures using a minimal invasive technique. The damage to the palmar carpal ligaments could be avoided and the scar would be much better [6] .

During open grafting in 50 cases of symptomatic nonunion, Shah and Jones encountered eight cases of fibrous union and elected to stabilize them with a compression screw. These eventually healed without bone grafting. Other authors have suggested that selected nonunion may heal with rigid fixation alone. Kim and Lee recorded union with slight resorption at the fracture site in 12 patients with delayed union of the waist of the scaphoid treated by percutaneous screw fixation [7].

Selected nonunited undisplaced fractures of the scaphoid, even those with a gap > $2 \mathrm{~mm}$, have the biological ability but not the mechanical stability 
for bone healing. If this is provided by percutaneous rigid fixation, these fractures will unite without requiring a bone graft.

Various surgical procedures have been introduced to treat scaphoid nonunion. Adequate bone graft and stable internal fixations are two important factors [8]. Screw fixation was superior to K-wire fixation as a treatment for unstable scaphoid nonunion [9]

Jones et al reported no significant difference in nonunion treated with a screw and those treated with K-wire $(p=0.62)$ the graft material was the important primary stabilizer and K-wire fixation would allow enough space for bone grafting. Pure cancellous chip bone harvested from the iliac crest had both the osteogenic features for osseous integration and the initial strength to resist physiological load [10]

The common sites of bone graft harvesting for scaphoid grafting are the iliac crest and the distal radius. Although there has been controversy on which is the best graft material, iliac crest grafts permit greater retrieval of marrow and more osteogenic mesenchymal stem cells. Therefore this source can provide superior osteogenic properties compared with graft from the distal radius. However, in terms of complications iliac crest bone graft has more donor site morbidity, such as pain, infection and hemorrhage [11].

It has been reported that a distal radius graft provides similar biomechanical strength as a conventional iliac crest graft in the treatment of scaphoid nonunion [12].

Chronic scaphoid waist nonunion typically leads to flexion and shortening of the scaphoid with carpal collapse. Reconstruction requires reestablishment of scaphoid length with correction of the flexion posture of the bone. In addition to healing, Amadio et al., found that individuals who regained normal scaphoid alignment, defined by a lateral intrascaphoid angle of less than $35^{\circ}$, were more likely to have satisfactory function and less likely to have arthritis than patients with greater intrascaphoid angles. This documents the importance of restoring normal carpal anatomy $[\mathbf{1 3 , 1 4}]$.

Corticocancellous bone from the distal radius has also been proposed. In fact, Christodoulou et al showed no statistical difference in time to union or union rate between iliac crest and distal radius graft. Tambe et al., showed equal union rates, but with a $21 \%$ incidence of donor site pain related to iliac crest [15].
Mark S. Cohen found with stable internal screw fixation, scaphoid waist nonunion with collapse and bone loss can be successfully treated using only cancellous bone graft. Advantages include marked simplification of surgical carpentry, the use of local autograft, and rapid incorporation of cancellous bone without compromise of scaphoid reduction and carpal alignment [15] .

In this study good results were achieved in both stable and unstable scaphoid nonunion by using pure cancellous bone graft either from the iliac crest or distal radius.

Slade et al., advocated the dorsal approach for treating these scaphoid fractures. They also used an arthroscopically assisted dorsal approach to stabilize nonunion without extensive sclerosis or bone resorption. Union was achieved in all cases, but they excluded those with cysts and sclerosis $>1 \mathrm{~mm}$, where there might not have been sufficient purchase for the screw thread in the proximal fragment. However, the dorsal approach has the disadvantages of damage to the articular cartilage of the proximal pole of the scaphoid and potential injury to the extensor tendons. Moreover, in order to insert the screw proximally, the wrist has to be fully flexed, causing the distal fragment to adopt a flexed position, there by producing the humpback deformity leading to malunion [16] .

Dinah et al., reported that There is a significant association between failure of operative treatment of scaphoid nonunion and a history of smoking (Fisher's exact test $p=0.02$ ). Bone grafting and internal screw fixation had a lower success rate in smokers than in non-smokers [17].

The results of this study suggest that patient age and delay from acute scaphoid fracture to nonunion surgery do not influence the outcome of this surgery. Nakamura et al., concluded from their series of 50 scaphoid non-unions, that functional outcome following bone-grafting was worse when surgery was performed more than 5 years after the original injury [18]

The high rate of union in this study is believed to be the result of careful selection of patients. Careful collection of preoperative data, close follow-up and easily recruitment of the patients and assessment of union by CT. scan.

The limitations of the study are the relatively small number of patients according to each grade and the fact that these techniques cannot be applied to many other patients with scaphoid nonunion. 


\section{Conclusion:}

This study proved that operative treatment of scaphoid nonunion can be summarized as follows: Grade I,II,III according to Slade and Geissler's classification can be treated by percutaneous or open fixation by Herbert screw even if the nonunion in prox. Pole Grade IV/V/VI we have to open volarly for waist or dorsally for prox. Pole and fixation with bone graft from iliac crest or distal radius.

In our study we chose the type of graft used according to presence or absence of deformity (DISI, humpback). So, if there was deformity we used iliac graft either wedgeor pure cancellous if there wasn't we used distal radius graft.

\section{References}

1- PHILLIPS T.G., REIBACH A.M. and SLOMIANY W.P.: Diagnosis and management of scaphoid fractures. Am. Fam. Physician, 70: 879-84, 2004.

2- RHEMREV S.J., VAN LEERDAM R.H. and OOTES D.: Nonoperative treatment of non-displaced scaphoid fractures may be preferred. Injury, 40 (6): 638-41, 2009.

3- SLADE J.F. III, GRAUER J.N. and MAHONEY J.D.: Arthroscopic reduction and percutaneous fixation of scaphoid fractures with a novel dorsal technique. Orthop. Clin. North Am., 32: 247-261, 2001.

4- DIAS J.J., WILDIN C.J., BHOWAL B. and THOMPSON J.R.: Should acute scaphoid fractures be fixed? A randomized controlled trial. J. Bone Joint Surg. Am., 87: 21602168, 2005.

5- BOTTE M.J., DOYLE J.R. and BOTTE M.J.: Surgical Anatomy of the Hand and Upper Extremity. Philadelphia: Lippincott Williams \& Wilkins, 3-91, 2003.

6- AMADIO P.C. and TALEISNIK J.: Green's operative hand surgery Churchil Livingstone edition, 2005.

7- TRUMBLE T.E., GILBERT M., JONE D.P. Jr., SMITH J., RAFIJAH G. and McCALLISTER W.V.: Displaced scaphoid fractures treated with open reduction and internal fixation with a cannulated screw. J. Bone Joint Surg. Am., 82: 633-41, 2000.
8- GRASA M. and MATHOULINB C.: Vascularized bone graft pedicled on the volar carpal artery from the volar distal radius as primary procedure for scaphoid non-union Orthopaedics \& Traumatology: Surgery \& Research, 97: 800-806, 2011.

9- MERRELL G.A., WOLFE S.W. and SLADE J.F.: 3 rd Treatment of scaphoid nonunions: Quantitative metaanalysis of the literature. J. Hand Surg. Am., 27: 685691, 2002.

10- BARTON N.J. and JONES D.B. Jr.: Experience with scaphoid grafting. J. Hand Surg. Br., 22: 153-160, 1997.

11- JARRETT P., KINZEL V. and STOFFEL K.: A biomechanical comparison of scaphoid fixation with bone grafting using iliac bone or distal radius bone. J. Hand Surg. Am., 32: 1367-1373, 2007.

12- FERNANDEZ D.L.: A technique for anterior wedgeshaped grafts for scaphoid nonunions with carpal instability. J. Hand Surg. Am., 9: 733-737, 1984.

13- AMADIO P.C., TALEISNIK J., D.P. GREEN R.N. and PEDERSON W. C.: Fractures of the carpal bones. Green's operative hand surgery, 4 th edition, Vol. 1, Churchill Livingstone, Philadelphia, 1999.

14- KAWAMURA K. and CHUNG K.C.: Treatment of scaphoid fractures and nonunions. J. Hand Surg. Am., 33 (6): 988-997, 2008.

15- CHRISTODOULOU L.S., KITSIS C.K. and CHAMBERLAIN S.T.: Internal fixation of scaphoid non-union: A comparative study of three methods. Injury, 32 (8): 625 630, 2001

16- JOSEPH SLADE F. III, WILLIAM B. GEISSLER, ANDREW GUTOW P. and GREG A. MERRELL: Percutaneous Internal Fixation of Selected Scaphoid Nonunions with an Arthroscopically Assisted Dorsal Approach the Journal of Bone \& Joint Surgery; J. Bjs. Org ., Vol. 85-A, Supplement 4, 2003.

17- DINAH A.F. and VICKERS R.H.: Smoking increases failure rate of operation for established non-union of the scaphoid bone International Orthopedics (SICOT), 31: 503-505, 2007.

18-NAKAMURA R., HORII E., WATANABE K., TSUNODA K. and MIURA T.: Scaphoid non-union: Factors affecting the functional outcome of open reduction and wedge grafting with Herbert screw fixation. Journal of Hand Surgery, British, Volume, 18: 219-24, 1993. 


\section{العلاج الجراحى لعدم آلتئام كسر الزورقية}

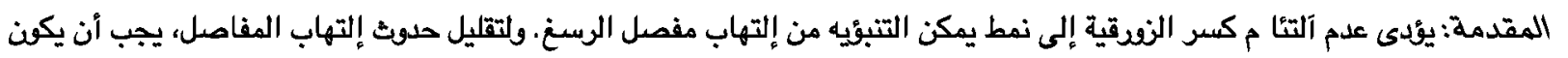

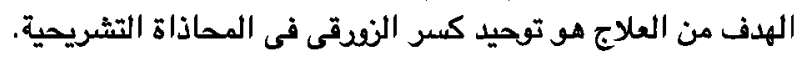
الهدف من الدراسة: تقييم الوسائل المختلفة لعلاج علم آلتئام كسر النقرقية وتقييم نتائجه الإكلينيكية.

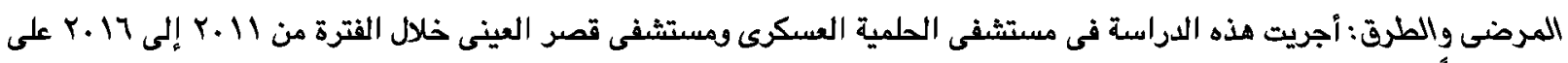

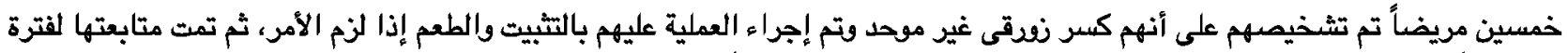

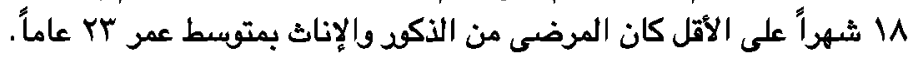

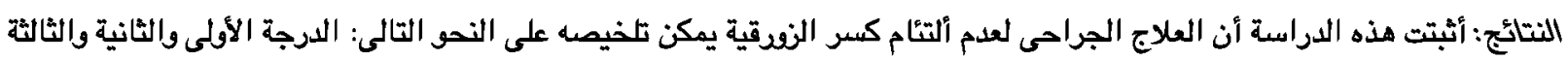

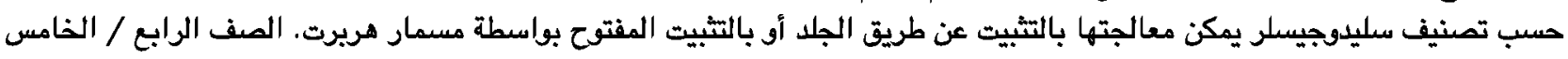

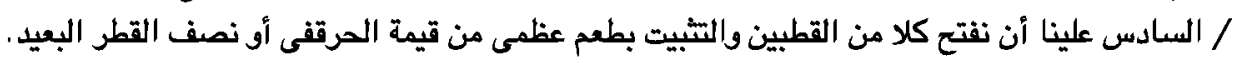

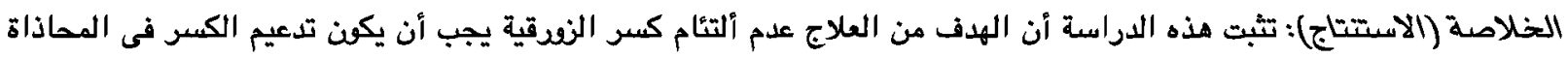

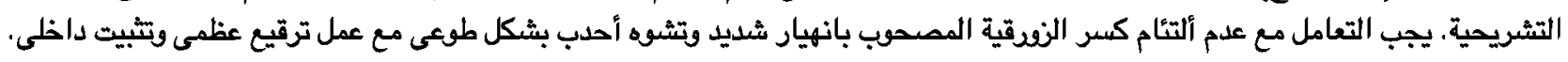

